\title{
Learning to Unlearn for Transformative Learning, an Epistemological Look
}

Jose Manuel Salum Tome, $\mathrm{PhD}^{*}$

Doctor in Education, Department of Education, Catholic University of Temuco, Calafquen 1100, Temuco

DOI: $10.36347 /$ sjahss.2020.v08i09.011

| Received: 10.09.2020 | Accepted: 18.09.2020 | Published: 28.09.2020

*Corresponding author: Jose Manuel Salum Tome, $\mathrm{PhD}$

Abstract

Review Article

Objective: Create awareness in teachers of the importance of the processes of learning to unlearn and relearn as part of our educational responsibility and continuous training. Summary: This paper corresponds to a reflection on various theories and approaches to learning and their relevance in the training of social agents, a reflection that emerges from the practice of training, and taking into account the fact that the meaning of what learning implies and how it is You learn is not at the center of the discussion in Latin American universities, in which what is taught is more emphasized than how to teach. The present work corresponds to a reflection about several theories and approaches of the learning and their relevance in the training of social agents, reflection that emerges from the practice of the training, and attending to the fact that the meaning of what it implies to learn and how it is that is learned is not at the center of the discussion in universities in Latin America, which emphasizes more what to teach rather than how to teach. Justification: The present work corresponds a reflection on various theories and approaches to learning and their relevance in the training of social workers, reflection that emerges from the practice of training, and considering the fact that the sense of what is involved in learning and how What is learned is not at the center of the discussion in universities in Latin America, in which more emphasis is placed on what to teach rather than how to teach. Without pretending to analyze praxis or be a guide on how to implement the transition from the prevailing training model, called informational, to another with a transformational nature, the working hypothesis on the training of social agents and, in particular, leadership training, is based on the importance of understanding the concept of learning, of how to learn and, therefore, of how to teach, since adults require unlearning, at the same time as learning, to achieve transformational learning that allows them not only to acquire new knowledge but also stimulate behavior modification in light of reviewing their own frames of reference. To achieve this proposal, the learners and also the teachers must review not only what they do, but how they think and who they are. The process is not only cognitive; it is also emotional and bodily. Therefore, a dynamic and integrated approach is proposed that works in the three fields and that in each one of them the concept of unlearning is the main idea. Additionally, a series of approaches are suggested, such as first, second and third cycle learning and paradigm revision; among others.

Keywords: Transformative Epistemological social agents Latin America awareness teach.

Copyright @ 2020: This is an open-access article distributed under the terms of the Creative Commons Attribution license which permits unrestricted use, distribution, and reproduction in any medium for non-commercial use (NonCommercial, or CC-BY-NC) provided the original author and source are credited.

\section{INTRODUCTION}

It is almost incredible that, in Higher Education and Training centers, more emphasis is placed on what is taught, content, and not on how it is taught, methodologies, and that more experts are hired in certain specialized areas of knowledge but not they have been trained in the methodological aspect.

Observations made in various educational centers in Latin American countries show that the pedagogical process itself is downplayed, and that this limitation does not only occur at higher levels of education, but also at secondary and primary levels, although in the latter the symptom is less. That is, less attention is paid to pedagogical development in higherlevel educational centers, generally focused on the search and transfer of knowledge as information, than in primary and secondary education centers, today, in Chile, under the reform process, precisely in the review of their pedagogical approaches.

And this does not happen due to a lack of theories and / or research in the field of epistemology, namely, authors such as Humberto Maturana and previously Paulo Freire, offer us a very reference point to understand that we should be concerned with how to 
teach from a knowledge of how is it that we learn, and, if learning is not adequate, how is it that we unlearn.

This problem is approached, by way of reflection, and some conclusions that are reached from the premises implicit in an analysis of the dynamic and essential process in education such as learning are shared in this document. And it is approached from the deepening of what is understood by learning and the usefulness of unlearning, postulating that this dynamic gives greater light to the teaching process.

The reflections that are presented are supported by more than a decade of experience in the training of young people in educational centers of different levels and of training carried out both for teachers and students, as well as exchange of ideas with colleagues in relation to the subject and specialized bibliographic review. Everything that was most relevant and pertinent to the subject was pointed out to give way to a proposal that is offered not to be a practical guide, but as a reflection that invites us to continue investigating and raising awareness that the problem subsists and is rooted in the work of educational centers.

So, the purpose of this work is, at the same time as a reflection, an invitation to educational agents to reconsider the concepts already mentioned: learn, how to learn, how to unlearn and therefore, how to teach. Also, to consider the hypothesis that maintains that adults require unlearning at the same time as learning, to achieve transformational learning, and thus contribute to dynamic and meaningful learning.

The document is organized in six sections. In the first, an attempt is made to analyze the approaches and concepts of traditional, informational education and learning, and why their permanence in current times and the need to move from this approach to one more in line with the rhythm of post-modern society, namely, a transformational approach. In turn, it leads to what is understood by education: object of analysis in the second section, which defines both transformative education and, as its variant, meaningful education. In light of the above, the third section opens a new key aspect for learning oriented to modify behavior, which for the author is the e sence of education and training. Likewise, it is carried out, in synthesis, the importance of the unlearning process and its link with vigorous learning.

In the fifth section, some possible learning strategies are briefly indicated that would make it possible to dynamize the process, giving relevance to teaching practice in the processes of change. In the sixth and last section, a final reflection is made that synthesizes and makes explicit the main proposals of this document: From information to transformation
Learning to unlearn for a transformative learning, an Epistemological look 1-Education and learning a stagnant process?

"The most perfect image of the Cosmos is the river ..." This sentence expressed by Heraclitus of Ephesus in the 6th century BC, to refer to the continuous evolution of what exists is today very applicable in the field of knowledge and therefore in relation to truths that sustain the human being. Then, given that the truths are constantly changing, a sort of negotiation occurs regarding which ones will or will not be accepted in order to attribute meaning to things, to events and to the human being himself. If this is so, it is contradictory to try to make teaching a simple process of transferring information from a subject who teaches (teacher or trainer) to a subject who learns (student or apprentice), moreover, it is an epistemological claim of a dogmatic nature. where the one who teaches pretends that knowledge is reduced to data and that he is the possessor of such knowledge.

What could we say then of the master classes? As knowledge transfer they are valid, but if we consider that knowledge is not something given, but rather it is built, as suggested by the cognitive theories of learning, among which we can highlight Piaget, Ausubel, Gagné, among others, we must conclude that all teacher-centered pedagogical practice is insufficient. Hence, it is necessary to review and / or generate strategies that promote discussion on issues that promote a change in perspective, which does not mean in any way suppressing the flow of information, but rather changing the form, viewing education not as a product, but as a process.

If we consider the approach of Mezisow (2000) and Kegan (1982, 1994, 2000) who, based on the approaches of Piaget and Freire, we can consider that a transformational approach is necessary, which implies looking at how it is learn, how it is thought, what we understand by education and what are the implications of transformative learning, aspects that will be considered below. As Mezisow says "Transformative learning refers to the process through which we transform established frames of reference (perspectives of meanings, habits of thought, mental frames... etc.) to make them more inclusive, discriminating, open, emotionally capable of changing and reflective, in such a way that they generate beliefs and opinions that prove to be more true and justified so that they generate action"

The permanence of the emphasis on the content or information seems to make sense if we take into account that the person who is capable of mastering a lot of information and transferring it is considered wise, either from European or North American authors, and who can cite these authors as support. To their knowledge, without further analysis or discernment. It is taken for granted that, if someone whose fame has 
transcended, what is said is true, and so should proceed. There is a kind of dependence on thought, a denial of the possibility of being authentic and generating new proposals more in line with reality. For example, the education in Finland is very good, its methodology, principles and values very pertinent, but for the Finns, not for Latin America.

Another reason for maintaining the tradition is the fear that teachers have of being confronted by students with questions that they may not be able to answer. They feel questioned in their wisdom and authority, since they assume the category of experts from the infallibility of their knowledge. Thus, the concept "education" refers to various meanings and theories, as many as perspectives of what is intended when you want to teach. But what we do agree on is that there is no unintended educational process, and necessarily behind each acceptance of the concept, an idea of society, of being human, and of learning is implicit.

If education is considered as a process of information transfer, a prevailing trend in the various educational fields, and in which this information is called by teachers "content" and by students "subject", the emphasis is on what teaching, and the concept of the student is that of a passive subject in which a standardized level of mastery of the content established as mandatory must be achieved. This is so from a behavioral perspective of learning where the response must be expected, uniform and quantifiable, from which it necessarily derives that knowledge is oversized as a simple cognitive process, of a rational and memory nature, and other elements that are not considered they are also combined in the learning process, as are the emotional and physical.

In this process focused on what to teach, the subject who learns in his capacity as a person is ignored, he is considered rather a passive entity that must be filled with information, this is what Freire called banking education in his work "Pedagogy of the oppressed" (1970) and from which I will take a fragment: "In banking education there are two different types of subjects, the educator and the student. The educator is the one who knows, the only one who has knowledge. He is the one who transmits his knowledge to the learner. The learner receives this knowledge from the educator without participating in the process, let's say it is like a filing cabinet ... This education refers to reality as something static, detained, divided with contents totally alien to the learner"

It is also necessary to consider that the rationalist and categorizing heritage of the GrecoRoman culture exerts its millenary influences on the ways of thinking of our Latin America, from Aristotle and his consideration of the human being as a rational animal to Hegel, ("Everything rational is real")
Descartes and Kant, among others, have paid homage to reason and set aside the set of affective and bodily capacities that are also involved in the learning process. Rational categorizations are useful, but they do not allow us to see reality in a complete way, not to understand ourselves in a changing world and in which we can dialogue from a holistic perspective.

Knowledge constitutes the main basis for the exercise of people, of their wealth and well-being and of society. The right to access knowledge gives the opportunity to participate in social, cultural and economic life, increasing any possibility of a true social inclusion, and at the same time increases the improvement of employability, through continuous education.

Now well, moving towards a knowledge society also implies inequalities and social exclusion reach. One effort that involves teaching is to bridge this gap and increase the educational level in adults and the incipient need for lifelong education.

In this sense, the challenges for the training of people today are much more extensive and complex, which increasingly refer to how to develop human resources for the benefit of each and every student in the school system, having as a center what they are the competencies that have the greatest impact on the growth as a whole person of the students.

\section{Knowledge about how cognitive processes work in the brain, allows}

- Develop the natural way in which the child's brain learns.

- Understand how the physical, emotional and intellectual domains naturally integrate in the child and provide an appropriate learning environment for self-discovery.

- Create meaningful, engaging experiences for children to explore, evaluate, and learn.

Knowing the neurobiological principles that govern children's cognitive and affective development provides the teacher with the tools to enrich and harmoniously enhance the talents of each student and thus allow learning to be a process that produces a relatively permanent change in the way of feeling, think and act of the student and teachers.

From the foregoing we can affirm that teaching is facilitating the conditions for the expected changes in student behavior to occur.

The question is: Where do we start?

For knowing the organ that allows us to be, learn, do, be, love, live and coexist, and that in our brain, which allows us to learn, unlearn and then relearn, from a young age and for continuing education. 


\section{Education as a meaningful process}

Our condition as social beings leads us to understand the educational process as a highly significant process, a process of encounter between two human realities with circumstances, beliefs, ideas and experiences: the subject who teaches and the subject who learns. These roles are not fixed, because it is an encounter between people, and people have a world that is their own and a world that is shared, and, in the shared one, today there is access to information in a fluid way through cyberspace. So, it is necessary to reaffirm the need to change the emphasis on education, and move it from the focus of what to teach, to how we learn, what are the factors that make effective and dynamic learning possible and what should be kept in mind when considering to the person of the learner.

First, the concept of learning must be rejected as an exclusively rational process, and at least two theories must be considered, that of multiple intelligences, Howard Gardner, and that of emotional intelligence, Daniel Goleman. The first considered that for the development of life one needs or makes use of more than one type of intelligence, which are presented as a network of autonomous sets related to each other, and among which we can mention mathematical logic, linguistics, spatial etc. And the second, Goleman, considers that the ability to recognize our emotions and those of others makes it possible to develop social skills, motivate ourselves, etc. Both theories are very important to broaden the understanding of the learning process and that must be taken into account when teaching. Add to this part of the message that Humberto Maturana, Chilean biologist and epistemologist, gave to educators in the Bío Bío region, Chile, at the ceremony to start the 2017 school year: "Amar educa. If we create a space that welcomes, that listens, in which we tell the truth and answer the questions and give ourselves time to be there with the child, that child will become a thoughtful, serious, responsible person who will welcome from itself. Being able to choose what to do, being able to choose if one wants what they chose or not... are some questions that appear".

Consider also the physiological factor, or body factor very underrated from traditional paradigms where duality prevailing mind-body as two complementary dimensions, but the light of modern theories, including contributions from 1 to neuroscience, we can understand that there at least three perceptual modalities or ways of receiving the information that comes to us from the outside and that condition our interpretation of that information, modalities that are recognized with the acronym VAK, to understand that there is different visual, auditory and kinesthetic modality in different types of subject. Based on this, it is understandable that not all students interpret the content presented by the teacher in the same way, if the surrounding reality is not the same for everyone, with which the complexity and richness of learning becomes more interesting and never uniform.

We can then consider that learning is, as the cognitive theories of Piaget, Vygotsky, and others propose it, a construction of meanings not only from one or more subjects, but also with interaction of the social and cultural environment, in which symbols, beliefs, expectations and ways of perceiving reality are combined to give meaning to what has been learned.

Considering learning in this way, the relationship between the subject who teaches, (or who intends to teach, in Freire's words), teacher or instructor, needs to be one of cooperation. Both, active subjects of the process, owe respect to their being as persons, in the fullest sense of the word, and in which the one who teaches becomes facilitated of the student's learning, who from the development of their potential and their own experiences give meaning to the experiences offered by the teacher for this purpose. This makes education a meaningful task, and with possibilities of a true social advance where each and every one can effectively learn to be, to know, to assert and assert.

\section{Learning as behavior modification}

In the words of Maturana, "To educate is to live together and, therefore, to agree to live together in a space of reciprocal acceptance in which the emotion and actions of those who live together are transformed according to the conversations that constitute that living together" (" The sense of the human ", 1992).

From this quote, I allow myself to point out as an indispensable requirement to say that learning has taken place, that it is reflected in the work of the learner and the teacher, given the dynamics of this process that is not for life, it is life.

The modification of behavior in any area in which it is required cannot be imposed, as it entails a value framework that is generated from the person as such, in their way of perceiving the environment and themselves. Learning modifies behavior yes and only yes when the change occurs in the subject as such, and this is possible with an education and / or training that considers and respects him as a person. For this, it is necessary to learn to unlearn and learn again according to the requirements of the time and space in which the subject or subjects are a task that is difficult, but necessary. (Some reasons that generate resistance to change have already been exposed) Unlearning as a dynamic strategy

In a world of constant change, the task of learning to unlearn is imperative, as already mentioned, especially in the field of education and training. Several authors have dealt with the subject, among others Moreno Olivos (2005) and Cegarra and Rodrigo (2004) 
who consider it necessary for teachers to learn to unlearn because they must prepare students to face the future. From its postulates, we can describe the sequence of steps necessary to unlearn:

1. Situate oneself in the here and now (reality): Recognize what happens and to whom it happens, assume that there are lessons from the past that are not valid in the present (now) and others that may be valid in another context, but not where it is located (here).

2. Distinction between personal opinion (subjective) and a general principle or rule. All subjects have personal experiences, but they cannot be taken as valid criteria for situations in another context. To get caught up in personal judgment is to abandon the possibility of growth and knowledge. This is a step that requires humility, and every human being has the right to have an opinion, but must recognize that this is... opinion.

3. Preparation of the personal and / or collective map. Objectively evaluate learning from the contrast between the interpretation of reality (map) and reality itself, a step that is possible only in the exchange of opinions, experiences and knowledge.

4. Search for new perspectives, understandings and solutions to evaluate if what is considered valid, what has been learned is still relevant, current and valid for the field to which it refers. If not, the next step is taken...

5. Unlearn: It is convenient to make a list of what has been considered "invalid" and proceed to its elimination. (This is the most difficult step, since the accumulation of knowledge is one of the most deeply rooted claims of wisdom in our Western culture, and there is a lot of literature about it). If this step is taken, the reconstruction continues, or rather, with the possibility of new learning.

6. Reconstruction of learning and sharing of these: This step needs to be done together, both in the generating phase and the installation or legitimation of them. Let us remember that every learning process is generated in coexistence with the other or others, in exchange spaces full of affection.

7. Return to transformed reality: New looks make new paths possible. Once the most significant aspects are reconsidered, a broader perspective is acquired that allows generating more pertinent, but never definitive, knowledge, therefore many times it will be necessary to unlearn again.

It is necessary to point out that, although the steps can be enumerated, this is not a mechanical process, as it is not a human process, it requires reflection on the subject and both individual and collective motivation, it is necessary to abandon the comfort of tradition to innovate, generating changes that bring us closer to the possibility of understanding our environment and ourselves.

\section{Unlearning is a complex phenomenon that has at least three limitations}

1. The individual factor given by resistance to change. Whether due to dogmatism, comfort, fear of innovation, there is, as has already been analyzed, a tendency to do the same and in the same way.

2. The biological factor: It is known, from neuroscience studies, that the brain has great plasticity, but this manifests itself more strongly in the first years of life, and decreases as one advances in age. However, if a constant activity of new neural connections, new learning is maintained, the brain responds adequately to changes even in adulthood, protecting itself from exercise and adequate nutrition.

3. The social factor: Social influences that reinforce negative views of the changes exist and weigh, being more common to highlight the failures than the successes. This, added to a strong successful and competitive conception, obstructs the possibility of innovation, mainly in the field of secondary schools, where studying is identified with absorbing content that is then measured with standardized tests.

Changes are possible to the $\mathrm{c}$ onsider transformative learning it is to overturn the traditional concepts and acquire the ability to constantly transform and develop in our students the same capacity, processing involving Cambar our frames of reference we had for sure, and be able to build new ones, more inclusive, demanding, open and flexible.

\section{Strategies that dynamize the unlearning process}

The studies that have been carried out in this regard emphasize resistance to change, but realize that it is possible. There are models that can be applied, of which there are successful experiences at different levels of education, and some are described by way of example:

1.- The inverted classroom or Flipped Classroom, which consists of changing the traditional method in which the teacher is the center of the class and whose task is to pass the contents to achieve learning in passive students who will have to incorporate them in a uniform way. The roles are reversed and now the students will be the protagonists of the process, and in an interactive process, they will learn dynamically. 
The characteristics of this model are more or less the following

a) The interaction of the students with the materials: this must be prepared in advance by the teacher and / or the students according to the objectives of the class. They can be cards, documentaries, videos, etc.

b) Use of ICTs (Information and Communication Technologies), which are available to everyone and which, when used in a programmed manner and with a clear purpose, allows access to up-to-date, diverse and relevant information. Content to be treated.

c) Active learning: it has been said that the shortcomings of traditional methods are, among others, the emphasis on what to teach, by inverting the class, the emphasis goes to how to learn, and with this model a dynamic learning is generated, active and participative, since it is the student who is discovering, with the help of the teacher, who has now become a guide and facilitator, the various possibilities of building knowledge from their own experiences.

d) It encourages dialogue, cooperation, autonomous thinking and the generation of ideas: Being a participatory model, the student feels responsible for the process, not in an individualistic way, but with a team spirit, eliminating that competitive desire that so much damage has been done to the formation of people. The collaboration that is achieved generates in the students senses of responsibility in the processes, also developing other essential necessary values such as respect, tolerance, and, by generating their personal vision, they dare to exchange ideas and base them.

e) It is a model that takes advantage of higher cognitive processes such as analysis, evaluation and application

Once students begin to appreciate the freedom provided by an open and collaborative model such as the Inverted Classroom, they will be more motivated to take control and conduct learning outside of the classroom.

2.- Problem-based learning (PBL) is a strategy that arises from the previous model, (AI) and whose purpose is for the student to build their learning, develop their skills and attitudes through real-life actions, which will allow the student to student will be able to analyze and face problems in the same way that they will in their professional development.

The most relevant feature of PBL is the use of problems as a starting point for the acquisition of new knowledge, which entails a leading role for the student and not for the teacher, who will become a facilitator of the process, not a transmitter of information. The process begins with presenting a problem, then learning needs are identified, needed information is sought, and then back to the problem.

It is a very valuable method because knowledge management is not based on the information given by the teacher; it focuses on the student's search for this knowledge, thus generating reflective practice, teamwork and adaptation to changes.

3. - Socratic Dialogues: Although it is true that today the use of ICTs is essential in teaching, so is discussion and thematic analysis. Learning to argue with fundamentals, express ideas, learn to listen, and be tolerant are also necessary lessons, and learning by doing recovers a fundamental role in the development of these skills.

In Socratic dialogues, the role of the teacher is also secondary, and consists of guiding the discussion based on themes and readings given in advance. Those who participate are the students, asking questions, giving opinions, highlighting the collected information. By opposing ideas, achieving consensus, students will form new judgments on the subject, giving rise to new learnings built together, and if doubts and / or points of disagreement are generated, new discussions, new research and perhaps new ones are generated consensus.

This methodology also dynamizes the educational process, and reinforces the possibility of unlearning and relearning, as it is worked methodically, it becomes an effective tool for the teacher.

When presenting these strategies, the entire development process described in the relevant bibliography has not been detailed, only a succinct description has been made as a way to invite people to venture into these and other similar strategies, now available to everyone in cyberspace and, if the need for it has really been understood, then we can say that transformational learning will be a reality.

\section{REFLECTION}

The topic of learning and learning to unlearn is a topic rooted in pedagogy and that runs through the entire educational process, and basically consists of daring to think and do things differently from how they have been thought and done previously, which requires having the audacity and courage to abandon security and dogmatism to enter the world of possibility. It is an essential concept in the process of But not only in education it is necessary to learn to unlearn, also in the business, environmental and social world in general, since the world is constantly changing and with it the sphere of knowledge.

To learn to unlearn we need to consider that learning is not just a passive process of a rational nature, it is also emotional and bodily, and, as we get 
older, it is more difficult to unlearn, since beliefs are more ingrained and plasticity is lost. Brain, unless we get into the habit of constantly innovating.

Learning to unlearn is a transformation process that turns us into active subjects, capable of generating significant changes both on a personal and social level, which leads to appreciating our environment and community life, discarding competition and success to enter a idea of more sustainable progress.

Although transformational learning is complex, as learning to unlearn is complex, it is possible and necessary, it invites us to reflect on ourselves and our work as human beings in a world of which we are part, and that of our ability to understanding the processes of change and adapting to them creatively will depend neither more nor less on our survival.

\section{REFERENCES}

1. webgraphy

2. www.eligeeducar.cl $>$ How children learn

3. conversingenpositivo.cl/.../ index.php?

4. www.monografias.com $>$ Education

5. https://www.nubemia.com/aula-invertida-otraforma-de-aprender/

6. https://www.goconqr.com/es/ensenar/inverted-aula

7. hhttps: //educrea.cl/aprendizaje-basado-enproblemas-el-metodo-abp/ttps: //www.cae.net/es/4pilares-fundamentales-del-aula-invertida-o-flippedclassroom /

8. $\quad$ sites.itesm.mx/va/dide2/ tecnicas_didacticas / abp / abp.pdf

9. https://inclusioncalidadeducativa.wordpress.com/ ..one 